\title{
Mental health consequences of long-term stays in refugee camps: preliminary evidence from Moria
}

Willemine van de Wiel ${ }^{1 *}$, Carla Castillo-Laborde ${ }^{2}$, I. Francisco Urzúa ${ }^{3}$, Michelle Fish ${ }^{1}$ and Willem F. Scholte ${ }^{4}$

\begin{abstract}
Background: Ever since the implementation of the EU-Turkey deal, most refugees that enter Greece via sea are confined to the island on which they arrive until their asylum claims are adjudicated, where they generally reside in camps. Some of these camps have detention-like characteristics and dire living conditions, such as Moria camp on the island of Lesbos, Greece. Aid-organizations have stated that the situation in camp Moria deteriorates the mental health of its inhabitants and there is qualitative evidence to support this. This study explores the quantitative relationship between the incidence of acute mental health crises and the length of stay in the camp.

Methods: A cross-sectional study was conducted using routinely collected data on 856 consultations of 634 different patients during 90 nights at an emergency clinic in Moria camp. Logistic regression analysis was used to explore whether the length of stay in the camp was predictive of the occurrence of an acute mental health crisis.

Results: Of the 634 patients, the majority were men (59.3\%), the average age was 23.2 years [0-71], and 24.3\% was $<18$ years. $25.5 \%(n=218)$ of consultations were related to mental health problems; $17.0 \%(n=37)$ of these met the study's case definition of an acute mental health crisis. Such crises were positively associated with the length of stay in the camp ( $p=0.011$ ); the odds ratio of a mental health crisis increases with 1.03 for every $10 \%$ increase in days of residence in the camp. This is notable when considering the average length of stay in the camp is 71 days.

Conclusion: This study offers quantitative support for the notion that the adverse conditions in Moria camp deteriorate the mental health of its inhabitants as suggested in qualitative research. Although this study does not provide evidence of causality, it is likely that the poor and unsafe living conditions, challenging refugee determination procedures, and a lack of mental health services in the camp are significant contributing factors. We urgently call for Europe's policymakers to honour the '51 Geneva refugee convention and terminate the neglectful situation on the Greek archipelago.
\end{abstract}

Keywords: Refugees, Camp, Greece, Containment, Mental health, Crisis

\footnotetext{
* Correspondence: w.vandewiel@gmail.com

${ }^{1}$ Moria Medical Support (MMS), Windroosplein 68b, 1018 ZW Amsterdam,

The Netherlands
}

Full list of author information is available at the end of the article

(c) The Author(s). 2021 Open Access This article is licensed under a Creative Commons Attribution 4.0 International License, which permits use, sharing, adaptation, distribution and reproduction in any medium or format, as long as you give appropriate credit to the original author(s) and the source, provide a link to the Creative Commons licence, and indicate if changes were made. The images or other third party material in this article are included in the article's Creative Commons licence, unless indicated otherwise in a credit line to the material. If material is not included in the article's Creative Commons licence and your intended use is not permitted by statutory regulation or exceeds the permitted use, you will need to obtain permission directly from the copyright holder. To view a copy of this licence, visit http://creativecommons.org/licenses/by/4.0/ The Creative Commons Public Domain Dedication waiver (http://creativecommons.org/publicdomain/zero/1.0/) applies to the data made available in this article, unless otherwise stated in a credit line to the data. 


\section{Background}

Over the last decade, millions of refugees have arrived in Europe, often by crossing the Mediterranean by boat or by traveling by land via Turkey, through Greece and the Balkans to Western Europe [1]. The number of people arriving rose slowly between 2010 and 2013 and then tripled in the 2 years that followed. In 2015, a record 1.3 million asylum applications were received in the EU [2], a situation that became known as the 'migrant crisis'. In efforts to reduce immigration through the EU borderstates, EU member states implemented various measures, notably the closure of the Balkan routes and the implementation of the EU-Turkey agreement in March 2016 [3].

While immigration via Greece substantially decreased following the EU-Turkey agreement, the length of stay for a refugee at the Greek entry locations drastically increased due to a prolonged administrative process [1]. Upon arrival, refugees generally reside in camps, which, even though originally designed as short-stay provision, became long-stay facilities. Some of these camps have detention-like characteristics and dire living conditions [4].

In accordance with the EU-Turkey deal containment policy, refugees are confined to the island on which they arrive until their asylum claims are adjudicated. Those who are deemed vulnerable (e.g. the elderly, sick, pregnant or those displaying severe mental health conditions) should be exempt from this policy and should be allowed to await the outcome of their asylum procedure on mainland Greece, where facilities are better [5]. However, the lack of accommodation on the mainland and delays in the vulnerability assessment procedure leave thousands of eligible individuals and families trapped on the island [5].

The island of Lesbos (or Lesvos) was, and still is a key entry point in Greece for refugees [6]. Hence, Lesbos houses several refugee camps, one of them being Moria camp, which has been repeatedly reported for being overcrowded, unhygienic, and unsafe [7-9] despite EU funding and the efforts of privately-funded nongovernmental organizations $[10,11]$. Charlie Yaxley, a spokesman for the UN High Commissioner for Refugees (UNHCR), reported the following about the camp in August 2018: "We are particularly concerned about woefully inadequate sanitary facilities, fighting amongst frustrated communities, rising levels of sexual harassment and assaults, and the increasing need for medical and psychosocial care" [12].

In Moria camp, few refugees feel safe and well-treated [13]. Psychological problems are omnipresent, and rates of attempted suicide are high [14]. Health care access is poor, especially for mental health care, and services are mostly provided by a changing group of medical volunteers [15, 16]. Multiple aid organizations have raised concerns about what they describe as a mental health crisis [7, 17]. They have pressed the EU member states and the Greek government to improve living conditions and decongest the island, arguing that the camp conditions negatively affect the mental health of its inhabitants [18].

The claim that the camp conditions like those in Moria adversely affect mental health has some empirical support. It has been well established that, compared to the general population, the prevalence of mental health conditions (in particular PTSD, anxiety, and depression) is higher in refugees and other conflict-affected populations [19] due to pre-migration stressors [20]. However, a growing number of studies in recipient countries found that imposed conditions of adversity, including prolonged detention or living in institutional accommodation, uncertain residency status, challenging refugee determination procedures, restricted access to services, and a lack of opportunities to work or study, combined in a way that compounded the effects of past traumas in exacerbating symptoms of PTSD and depression in this population [21, 22]. In a series of studies, Miller et al. stressed the mediating role of daily stressors such as unsafe living conditions, challenges in meeting basic survival needs (access to water, food, shelter, healthcare), the inability to produce income, and isolation from family and traditional social supports, on the effect of past war-related trauma on mental health in refugees [23-25]. In a study in two Rohingya refugee camps, it was found that, while PTSD symptoms were associated with both prior trauma exposure and environmental stressors (problems with food, lack of freedom of movement, and concerns regarding safety), depression symptoms were associated with daily stressors only [26]. Studies that focus on the relation between the length of time spent in the asylum procedure (be it in immigration detention, a refugee camp, or another institutional accommodation) and mental health find a cumulative adverse effect [27-29]. In turn, release from detention or being granted a permanent visa improves mental health [30, 31].

Two qualitative studies examining the link between Moria camp conditions and mental wellbeing both suggest that camp conditions (lack of safety and proper living conditions, institutional abuse, slow and constantly changing asylum procedure, lack of (mental) health service provision, lack of functional and supportive networks) lead to a deterioration in mental health [32, 33]. This effect, however, has never been quantified.

This study aims to establish the relationship between the length of stay in Moria camp and mental health by using quantitative data provided by Moria Medical Support (MMS), a Dutch-registered medical NGO. MMS provided emergency medical care in Moria between nine 
o'clock in the evening and eight o'clock in the morning, 7 days a week. As expected, working conditions were challenging because of limited resources and a lack of safety. See Table 1. We hypothesized that given the prevailing stressors (lack of safety, challenges in access to water, food, shelter, and healthcare, inability to produce income, lack of supportive networks, institutional abuse, and uncertainty regarding the length of the asylum procedure), a longer length of stay in the camp would negatively impact mental health.

Restricted by the nature of clinical activities at the MMS clinic and the healthcare situation in the camp, we focused on the relationship between length of stay and the incidence of acute mental health crises rather than mental health conditions in general. This will further be clarified in the Methods section.

Ethical approval was waived by the Ethics Committee of Santiago's Universidad del Desarrollo, Chile, as the study only made use of data from secondary sources, routinely collected, anonymized information on patients.

\section{Methods}

\section{Study site and period}

The night clinic of MMS provided emergency medical care for all residents of Moria from January to April 2018 (when the clinic was demolished), 21:00 to 08:00 h, 7 days per week. Data used for this study were collected over this period. During this period, the camp population size fluctuated between 5560 and 6429 people [34]. Children $(<18$ years $)$ constituted at least $30 \%$ of the camp population [35].

\section{Dataset}

An anonymized database was provided by MMS, comprising the routinely collected information on 1206 clinical consultations with 937 unique visitors on 90 different days. For some patients, relevant data were missing, meaning that the final sample comprised 856 consultations from 634 unique patients. Apart from medical details (problem, diagnosis, and treatment), information was documented on patients' gender, age,

\section{Table 1 The clinic's working conditions}

\footnotetext{
The clinic consisted of a container with three small consultation rooms. Unable to gain medical access during the day, patients of all ages and nationalities would line up well before opening hours. A triage system was used to ensure that the worst cases were addressed, adding to desperation and anxiety in those turned away. Inside the clinic, there was often agitation and noise; earplugs were sometimes handed to patients to prevent panic or dissociation from being triggered. MMS staff had to lock themselves in and call the police on a regular basis, mostly because of threatening or aggressive patients. On one occasion, 20 armed men attacked the clinic, trying to assault a patient who was inside. The night watch of the police was outnumbered and could not prevent the clinic from being demolished and patients and staff inside being assaulted. It marked the end of the clinic's activities.
}

country of origin, and an indication of the length of stay in the camp at the time of consultation. Categorization of raw medical data was done in retrospect by the first author of this article. ${ }^{1}$

\section{Study design and data analysis}

In this cross-sectional study, in addition to descriptive analysis, logistic regression analysis was performed using the length of time in the camp in days as an input variable, together with age (in years), gender (dichotomous variable, one if male), and country of origin as possible confounders. The output variable was 'acute mental health crisis'. As substantiated in the below paragraph 'Dependent variable', 'acute mental health crisis' was defined for this study as encompassing three conditions: a) self-harm, as constituted by a non-accidental selfinflicted wound, the majority being skin cutting; b) a suicide attempt as constituted by an action with suicidal intent, in which either the seriousness of the intent or the resulting injuries warranted immediate referral to (in-hospital) specialized care; c) a severe state of panic and/or agitation and/or dissociation and/or psychosis as constituted by anxiety, nervous agitation, undirected aggression, alienation or disturbed reality testing, causing disturbed behavior resistant to non-invasive treatment (i.e., adequate psychological approach, relaxation and grounding techniques, or/and oral psychotropic medication) and thus requiring intramuscular psychotropic medication.

Demographic (age and gender) and displacement characteristics (country of origin) were described, as well as a general overview of the mental health consultations. The analysis considered the average, minimum, and maximum for continuous variables (age and length of stay) and the percentage distribution for categorical variables (country of origin and causes of consultation).

Two sets of logistic regressions were conducted with all the consultations for which we have complete data using the manifestation of any of the conditions covered by this study's case definition as a dependent variable (value of one if present, zero otherwise). Trying to understand the importance of each of our demographic characteristics, in our first set of regressions, we conducted a bivariate analysis, including each of these variables independently. We then regressed our displacement characteristics, a set of dummies for the country of origin. In our second set, the multivariate analysis, we focus on the duration of stay as an independent variable, while also including country of origin, age and gender, as the prevalence of mental health disorders vary with gender [36] and through individuals' lifespan [37, 38].

\footnotetext{
${ }^{1}$ As a robustness test, the categorization for acute mental health crisis was double-checked by WFS and we re-ran our main analysis, with results (odds ratio's) remaining unchanged.
} 
All statistical analyses were performed using STATA version 16 software. ${ }^{2}$

\section{Dependent variable}

A mental health crisis can be defined as any situation in which a person's behavior puts them at risk of hurting themselves or others, or prevents them from being able to care for themselves and function effectively in the community [39]. It can be seen as the manifestation of an exacerbated mental health condition or of the sudden collapse of an unstable psychological balance. As a case definition, we used the three conditions mentioned in the first part of the 'Study design and data analysis' paragraph above.

The focus on the relationship between the length of stay and the incidence of acute mental health crises rather than on mental health conditions in general has two main reasons. First: the number of mental health conditions identified at the MMS clinic could not be expected to be indicative of the incidence of mental health conditions in the camp population for various reasons. Help-seeking behavior depended on many factors such as demographic variables like gender and age [40], on cultural background [41], and on safety as experienced during the nightly opening hours of the clinic. The clinic was known to offer only Psychological First Aid (PFA) and psychiatric crisis management. Patients who were not in crisis were sensitized to visit psychosocial programs by other NGOs during the daytime. Only rarely short-term access to mental health services (like that of Médecins Sans Frontières, MSF) was negotiated since only the worst cases were accepted. As a result, nonurgent patients might not have been inclined to revisit the clinic unless they were (close to) being in crisis. A second reason to focus on mental health crises as the dependent variable was the fact that few of the volunteer medical staff at the MMS clinic were qualified in psychiatric diagnosing and even if they were, there was simply no time for a comprehensive assessment.

In addition, using acute mental health crises as the dependent variable comes with advantages. The association between the presenting rate of acute mental health crises at the clinic and the incidence of such crises in the camp is likely to be strong, as patients with serious suicide attempts, significant self-harm, and severe panic/ agitation/dissociation/psychosis tended to be brought to the clinic by bystanders if they would not come on their own accord. We added 'resistant to non-invasive treatment' to the third condition to differentiate between relatively mild or self-limiting crises (patients that might

\footnotetext{
${ }^{2}$ We performed two robustness tests (King and Zeng's rare event logit and Poisson regression), as it could be argued that the event's frequency is relatively low. Our results remained unchanged.
}

have stayed at their dwelling) and more serious cases (patients that were likely to be brought to the clinic by the community if not coming on their own accord). Moreover, the identification of an acute mental health crisis in the dataset is straightforward, despite the diagnostic limitations of the clinic; symptoms were overt, treatment was invasive (injection/stitching), or presentations warranted immediate referral.

\section{Results}

Table 2 shows the demographic and displacement characteristics for the refugees in the study sample $(n=634)$. The majority were men $(59.3 \%)$ of Syrian $(31.4 \%)$ or Afghan (26.5\%) origin, while the average age was 23.2 years $[0-71]$, and $24.3 \%$ were children $(<18$ years). The average length of stay in the camp until consultation was 70.9 days [0-532]. A total of 143 individuals presented with mental health problems. Those with an acute mental health crisis $(n=25)$ were mostly Iraqi $(42 \cdot 3 \%)$ men (88.0\%), with an average age of 23.8 years [15-36]. The average length of stay until consultation for this group was 105.9 days [2-471]. Individuals presenting with nonacute mental health problems $(n=118)$ were mostly from Democratic Republic of Congo - DRC (52.5\%), male (69.5\%), with an average age of 24.9 [12-66], and an average length of stay until consultation of 67.9 days [1-532].

Some individuals presented more than once with mental health problems, whether or not acute. The individuals with mental health problems $(N=143)$ had in total 218 mental health-related consultations (25.5\% of all consultations) (Table 3). Acute mental health crises represented $17.0 \%(n=37)$, with selfharm (6.9\%) and severe panic/agitation/dissociation/ psychosis (6.4\%) being the most common, followed by suicide attempt $(3.7 \%)$. The most relevant other mental health consultations (83.0\%) were trauma-related symptoms $(28.9 \%)$ and mild to moderate panic/agitation/dissociation/psychosis (23.4\%). There was no significant difference between included and excluded consultations in terms of incidence of acute mental health crises.

Table 4 presents the results of a logistic regression analysis we performed with each of our demographic and displacement characteristics independently, showing that the male gender is significantly associated with increased odds of acute mental health crises, whereas age does not seem to increase these significantly. Length of stay (days in $\log$ ) increases the odds of acute mental health crises, with a $10 \%$ increase in the number of days increasing the odds ratio by 1.032 . The last column shows that refugees from DRC are less likely to suffer acute mental health crises, with the opposite being true for those from Iran, Iraq and Syria. 
Table 2 Refugee demographic and displacement characteristics

\begin{tabular}{llll}
\hline Refugee characteristics & Total $(\boldsymbol{n = 6 3 4 )}$ & $\begin{array}{l}\text { Acute mental health } \\
\text { crisis }(\boldsymbol{n}=\mathbf{2 5})\end{array}$ & $\begin{array}{l}\text { Other mental health } \\
\text { presentations }(\boldsymbol{n}=\mathbf{1 1 8})\end{array}$ \\
\hline Nationality (\%) & & & $15.1 \%$ \\
$\quad$ Syria & $31.4 \%$ & $11.4 \%$ & $12.7 \%$ \\
Afghanistan & $26.5 \%$ & $42.3 \%$ & $16.9 \%$ \\
Iraq & $20.7 \%$ & $7.7 \%$ & $52.5 \%$ \\
Democratic Republic of Congo & $15.8 \%$ & $7.7 \%$ & $0.8 \%$ \\
Iran & $3.8 \%$ & $15.4 \%$ & $0.8 \%$ \\
Other & $1.9 \%$ & $88.0 \%$ & $69.5 \%$ \\
Male & $59.3 \%$ & $23.8[15-36]$ & $24.9[12-66]$ \\
Age (years) & $23.2[0-71]$ & $4.0 \%$ & $7.6 \%$ \\
Children (<18 years) (\%) & $24.3 \%$ & $105.9[2-471]$ & $67.9[1-532]$ \\
Stay until consultation (days) & $70.9[0-532]$ & & \\
\hline
\end{tabular}

In Table 5, the multivariate analysis includes all of our demographic and displacement characteristics. The results are consistent with the univariate analysis. The length of stay in Moria camp (in log) is significantly associated with increased odds of 1.402 ([1.081-1.819]; $p=0.011$. A $10 \%$ increase in the number of days spent at the camp increases the odds ratio by 1.033 . There are still decreased odds with DRC as a country of origin and increased odds with Iran, Iraq, and Syria as the country of origin. The factor of gender lost its significance, and age is still not significantly associated with the odds of an acute mental health crisis.

\section{Discussion}

This cross-sectional study among refugees in Moria camp on Lesbos, Greece, examined the incidence of acute mental health crises and their relationship with the length of stay in the camp. The data used were collected from 856 consultations during 90 nights at an emergency night clinic in the camp. While $25.4 \%$ ( $n=$ 218) of the consultations were related to mental health

Table 3 Type and frequency of mental health consultations

\begin{tabular}{ll}
\hline Type & Total $(\boldsymbol{n}=\mathbf{2 1 8})$ \\
\hline Acute mental health crisis & $17.0 \%$ \\
Severe Panic/Agitation/Dissociation/Psychosis & $6.4 \%$ \\
Self-harm & $6.9 \%$ \\
Suicide attempt & $3.7 \%$ \\
Other mental health presentations & $83.0 \%$ \\
Trauma related symptoms & $28.9 \%$ \\
Mild to moderate Panic/Agitation/Dissociation/ & $23.4 \%$ \\
Psychosis & \\
Low mood and/or suicidal ideation & $11.9 \%$ \\
Other & $18.8 \%$ \\
\hline
\end{tabular}

problems, $17.0 \%(n=37)$ of these met the study's case definition of acute mental health crisis.

Acute mental health crises were significantly and independently (the multivariate analysis corrects for interaction between the input variables) associated with the length of stay in the camp $(p=0 \cdot 011)$. The established association implies that the odds ratio of experiencing such crisis increases with 1.033 for every $10 \%$ increase in days of residence. This is significant when considering the average length of stay in the camp ( 70.9 days). Other factors associated with acute mental health crises were Iranian/Iraqi/Syrian ethnicity, augmenting the risk, while Congolese ethnicity reduced the risk. The male gender was significantly associated with a crisis in the univariate analyses, but gender lost its significance in the multivariate model $(P=0.102)$. We failed to find a significant association between acute mental health crises and age 38 .

The limited information in the database prevented us from investigating prior mental illness as a possible confounder. However, we deem it very unlikely that the found correlation between acute mental health crisis and the length of time spent in the camp is positively impacted by prior history. If anything, it would reduce the size of this correlation. Patients with a severe physical or mental condition are granted a vulnerability status that entitles them to await the outcome of their asylum application in another facility. Although the transfer is not always effectuated, it is safe to assume that a prior mental health condition does not prolong the duration of the time spent in the camp. Furthermore, one would expect refugees with a previous history of mental illness to suffer acute crises more often than those without, meaning that they would likely have presented themselves after a shorter length of stay in the camp.

This study offers quantitative support for the notion that Moria camp deteriorates mental health, as suggested by qualitative reports in scientific journals [32, 
Table 4 Logistic regression odds ratios (OR), 95\% confidence intervals [in brackets] and p-values for various refugee characteristics (left column) as predictors of acute mental health crisis (right columns)

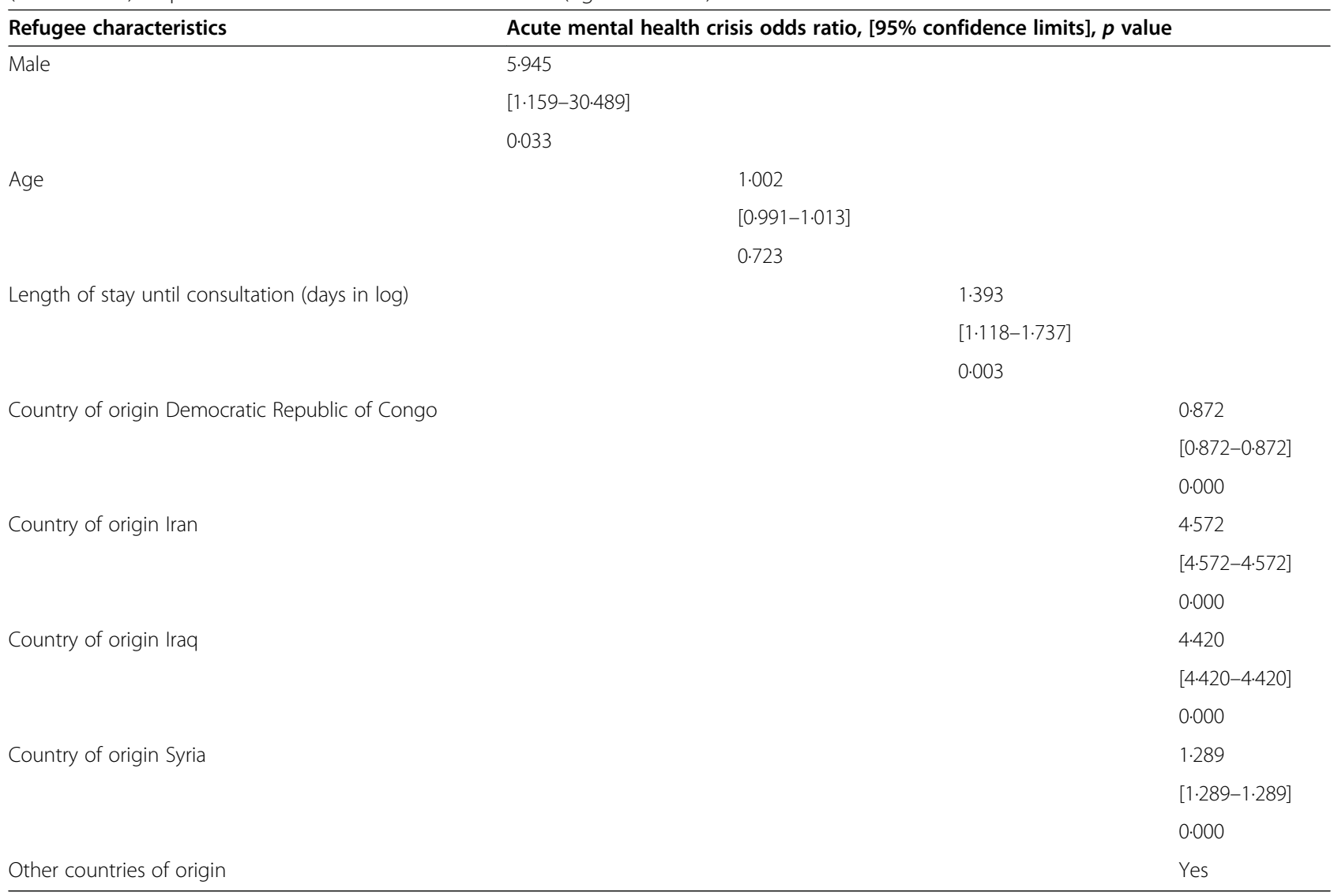

33], and communications by aid workers [7, 18]. Our findings are in line with previous research investigating the effect of post-migration stressors in refugee facilities on mental health, as discussed in the introduction. Furthermore, by focusing on acute mental health crises, our study extends the existing evidence related to the prolonged asylum process's detrimental mental health effects due to adverse living conditions. Exacerbations of mental health conditions do not only add to the suffering of the affected individuals, but also to 'collateral damage' in various forms, ranging from serious destabilization of the social environment to physical harm to others in the person's environment, all of which may traumatize an already vulnerable population, children in particular [17]. While the current policy detains refugees at Lesbos, the negative mental health implications of immigration detention [28] are believed to continue after release [42], eventually affecting successful integration in future host societies [43].

Our study also provides some understanding of the magnitude of the problem. Thirty-seven acute mental health crises in 3 months on a population of circa 6000 inhabitants may not seem remarkable; this number, however, reflects only a minor part $(17 \%)$ of the total mental health presentations that were selected through the triage system of the overnight emergency clinic. When one would extrapolate this presentation rate to the context of a small European hospital (catering for a population of 100,000 inhabitants), it would compare to 40 mental health presentations per night, amongst them 3 cases of self-harm, 2-3 patients needing invasive drug treatment and 1-2 serious suicide attempts.

These substantial numbers are likely to be more than an effect of premigration trauma and the asylum procedure, but also a result of the poor and unsafe living conditions, challenging refugee determination procedures, and a lack of mental health services in the camp, as explained in the Introduction section of this article. It also indicates that access to mental health care during the day fell seriously short, as was already suggested by qualitative reports $[15,16,32]$.

The observation that the risk of an acute mental health crisis varies amongst refugees of different nationalities cannot be directly linked to past literature. Elaborating on possible causes falls well beyond the scope of this article but might be interesting for follow up research. That the male gender seems to predispose to an acute mental health crisis (although not significantly so in this study), 
Table 5 Logistic regression odds ratios (OR), 95\% confidence intervals [in brackets] and p-values for various refugee characteristics (left column) as predictors of acute mental health crisis (right columns)

\begin{tabular}{llcc}
\hline Refugee characteristics & \multicolumn{1}{c}{ Acute mental health crisis odds ratio, [95\% confidence limits], $\boldsymbol{p}$ value } \\
\hline Male & 4.607 & {$[0.739-28.722]$} & 0.102 \\
Age & 1.002 & {$[0.992-1.013]$} & 0.675 \\
Length of stay until consultation (days in log) & 1.402 & {$[1.081-1.819]$} & 0.011 \\
Country of origin Democratic Republic of Congo & 0.726 & {$[0.601-0.877]$} & 0.001 \\
Country of origin Iran & 4.307 & {$[3.402-5.453]$} & 0.000 \\
Country of origin Iraq & 3.937 & {$[3.294-4.707]$} & 0.000 \\
Country of origin Syria & 1.238 & {$[1.093-1.402]$} & 0.001 \\
Other countries of origin & & Yes &
\end{tabular}

complies with literature. Although women (refugees and non-refugees alike) are reported to suffer more from anxiety and depression and perform more deliberate self-harm [44-46], serious suicide attempts, completed suicides and admissions to a psychiatric intensive care unit are more common in men [47-49]. In addition, men in general show higher levels of externalizing (disruptive and violent behavior) and substance abuse [50] and refugee men have an increased risk of psychosis [51]. Although expected, a relation between age and acute mental health crisis could not be objectified in our model. This may be the effect of the non-linear relation of age with mental health morbidity $[37,38]$.

This study, based on real-world frontline data, gives an impression of the level of acute distress experienced by refugees stranded on the Greek islands. However, it has several limitations, mostly related to data availability. An initial limitation is that the average length of stay for the camp inhabitants could not be quantified, as no data could be collected on a population level, which might have led to an unavoidable selection bias. A second limitation is that there was probably a higher incidence of acute mental health crises than the one estimated in this study. As described in Table 1, medical documentation might have been problematic due to difficult working conditions, for example patients being too aggressive and/or intoxicated, meaning that not all refugees suffering an acute mental health crisis were included. Furthermore, acute mental health crises that were professionally addressed during the daytime clinic hours were not seen by MMS, thus not included in the study sample. Lastly, no data exists on actual suicides. Given the serious nature of some attempts reported or identified at the night clinic, one might assume other attempts to have resulted in death. Relevant data, however, were not available.

Another limitation was methodological in nature. The concept of an 'acute mental health crisis' is usually not defined in terms of pathology $[52,53]$, but by the involvement of an ambulant crisis team or hospital admission of a patient. Due to the near absence of mental health services for the camp inhabitants, the diagnostic limitations of the clinic's personnel, and the summary information in the database, such a definition would not suffice. With the pragmatic but narrow definition operated for this study, however, some patients were excluded that would under normal circumstances be admitted to a mental health facility.

We believe that a camp-wide cross-sectional or prospective cohort study design with standard psychiatric interviewing would have been preferable in terms of methodology. However, it was not possible to conduct such a study for the authors of this article. The main reasons were our limited means (no funding) and capacity (limited qualified personnel), the organization of the camp, and the political sensitivity. There was no funding to perform a camp-wide survey followed by the necessary psychological follow up in this vulnerable population. Furthermore, while conducting a survey would require permission from the Greek army, which formally directed Moria camp, Greek authorities have not been forthcoming with exposing the camp conditions. Only a handful of NGOs were allowed access to the camp premises, media were generally banned, and journalists have even been arrested on instigation of the Ministry of Defense after publishing information related to Moria camp [54].

To date, facilities for refugees on Lesbos and the other Greek islands have not improved since the EU-Turkey deal, which was signed almost 5 years ago. Meanwhile, camp populations have tripled or quadrupled, depleting not only the stamina of the refugees, but also exasperating island inhabitants. We hope this paper adds to the understanding of the adverse consequences of the current situation for the medical world and Europe's policymakers.

\section{Conclusion}

This study, based on frontline medical data collected in 2018, offers quantitative support for the notion that the adverse conditions in Moria camp (Lesbos, Greece) lead 
to a deterioration in mental health, as suggested by qualitative studies and in communications by aid workers. It also offers an insight into the magnitude of the mental health burden in the camp as well as the lack of mental health services.

While acknowledging that this study does not provide evidence of a causal relationship between the length of stay and mental health crises, it is fair to suggest that the poor and unsafe living conditions, challenging refugee determination procedures, and a lack of mental health services in the camp are significant contributing factors. We urgently call for Europe's policymakers to honor the '51 Geneva refugee convention and terminate the neglectful situation on the Greek archipelago.

\section{Post scriptum}

On the ninth of September 2020, during this manuscript's revision process, Moria camp was largely destroyed by a fire believed to have been set by some of its inhabitants. The perpetrator(s) might be portrayed as ungrateful and dangerous refugees, trying to manipulate their way out of the island. We hope this paper sheds a different light on the matter. Although fire-setting in a refugee facility is not uncommon $[55,56]$, it is usually performed by outsiders. As a matter of self-interest, people do not set fire to their place of refuge, putting their own and other lives in danger. However, at Lesbos, refugees found despair next to refuge. Here, the criminal act of arson may have acted as the expression of utter despair.

\section{Abbreviations}

MMS: Moria Medical Support (a Dutch registered Medical NGO);

EU: European Union; UN: United Nations; UNHCR: United Nations High Commissioner for Refugees; NGO: Non-governmental organization; PTSD: Post-traumatic stress disorder

\section{Acknowledgements}

We would like to thank MMS for making the data available for us Furthermore we want to thank Samira Hänska and Tuva Schröder for their work on data transcribing and data cleansing, supported by Joost van de Wiel and Hubert Daglio, and Luca Fontana for being a sparring partner from the earliest stage.

\section{Authors' contributions}

WW had the original idea for the paper as she was connected with the NGO. She categorized the data and was involved in the literature research and writing the of paper. CCL and FUI were jointly responsible for the study design, the data analysis, and compiling the tables. Further, they have also supported the literature search and article writing. MF was in charge of database management from a technical perspective (merging data sets, data cleansing, formatting and anonymization). As the expert in the field, WFS contributed to the writing and supervision of the writing process and double-checked the data categorization for the dependent variable. All authors have read and approved the final manuscript.

\section{Authors' information}

WW is a MD specialized in Family Medicine who has been working for different NGO's in a number of refugee camps worldwide. CCL is Assistant Professor of the Centro de Epidemiología y Políticas de Salud at the Universidad del Desarrollo in Santiago, Chile, with research focus on public health and health economics. MA in Economics with a major in public policy from Pontificia Universidad Católica de Chile and MSc in International Health Policy (health economics) from the London School of Economics and Political Sciences.

FUI is currently reader in finance at Bayes Business School, City University of London, having worked previously as Assistant Professor of Finance, Erasmus University in the Netherlands.

MF is a freelance business analyst graduated in economics at the University of Wisconsin, USA. WFS is a psychiatrist and longstanding researcher at the University of Amsterdam. He holds a PhD in mental health in war-affected populations. He was at the Board of Médecins sans Frontières Holland for over 10 years, during which he helped design and supervise mental health and psychosocial support programs.

\section{Funding}

None

\section{Availability of data and materials}

Datasets analyzed for the current study were provided by MMS. Requests for data sharing can be directed to the corresponding author, who will discuss the meeting of requests with MMS board members.

\section{Declarations}

\section{Ethics approval and consent to participate}

A written permission to use the datasets for this study was provided by MMS. As data used were retrieved from an existing anonymous database only comprising data that had routinely been collected within the framework of patient care, there was no need for ethical approval. This was confirmed by the Ethics Committee of Santiago's Universidad del Desarrollo, Chile. Therefore, no local ethics committee was approached for approval. All methods were performed in accordance with the relevant guidelines and regulations.

\section{Consent for publication}

Not applicable

\section{Competing interests}

The authors declare that they have no competing interests.

\section{Author details}

${ }^{1}$ Moria Medical Support (MMS), Windroosplein 68b, 1018 ZW Amsterdam, The Netherlands. ${ }^{2}$ Centro de Epidemiología y Políticas de Salud, Facultad de Medicina Clínica Alemana, Universidad del Desarrollo, Av. Las Condes 12, 438 Lo Barnechea, Chile. ${ }^{3}$ Faculty of Finance, Bayes Business School, City University of London, 106 Bunhill Row, London EC1Y8TZ, UK. ${ }^{4}$ Amsterdam UMC, Department of Psychiatry, University of Amsterdam, Meibergdreef 5, 1105 AZ Amsterdam, The Netherlands.

Received: 16 February 2021 Accepted: 9 June 2021

Published online: 02 July 2021

\section{References}

1. UNHCR. Regional Refugee and Migrant Response Plan for Europe - 2017 | Global Focus [Internet]. [cited 2019 Jul 11]. Available from: http://reporting unhcr.org/node/17167

2. NW 1615 L. St, Suite 800Washington, Inquiries D 20036USA202-419-4300 | M-857-8562 | F-419-4372 | M. Record 1.3 Million Sought Asylum in Europe in 2015 [Internet]. Pew Research Center's Global Attitudes Project. 2016 [cited 2020 Aug 17]. Available from: https://www.pewresea rch.org/global/2016/08/02/number-of-refugees-to-europe-surges-torecord-1-3-million-in-2015/

3. EU-Turkey statement, 18 March 2016 [Internet]. [cited 2020 Aug 28]. Available from: http://www.consilium.europa.eu/en/press/press-releases/201 6/03/18/eu-turkey-statement/

4. Avenue HRW| 350 F, York 34th Floor | New, t 1.212.290.4700 N 10118-3299 U|. Greece: Dire Conditions for Asylum Seekers on Lesbos [Internet]. Human Rights Watch. 2018 [cited 2019 Jul 22]. Available from: https://www.hrw.org/ news/2018/11/21/greece-dire-conditions-asylum-seekers-lesbos

5. Moutafis G. Vulnerable and abandoned: How the Greek reception system is failing to protect the most vulnerable people seeking asylum - Greece [Internet]. ReliefWeb. [cited 2019 Sep 16]. Available from: https://reliefweb. 
int/report/greece/vulnerable-and-abandoned-how-greek-reception-systemfailing-protect-most-vulnerable

6. UNHCR. Mediterranean Situation, sea and land arrivals [Internet]. [cited 2019 Jul 11]. Available from: https://data2.unhcr.org/en/situations/mediterranean/ location/5179

7. Kitsantonis N. Greece's Biggest Migrant Camp Is a Mental Health Crisis, Aid Groups Say. The New York Times [Internet]. 2018. [cited 2019 Jul 11]; Available from: https://www.nytimes.com/2018/09/25/world/europe/greecemigrant-camp-mental-health.html

8. A Lesbos, le cauchemar des réfugiés de Moria. Le Monde.fr [Internet]. 2017. [cited 2019 Jul 21]; Available from: https://www.lemonde.fr/ europe/article/2017/12/13/a-lesbos-le-cauchemar-des-refugies-de-moria_ 5229015_3214.html

9. Rare look at life inside Lesbos' Moria refugee camp [Internet]. [cited 2019 Jul 21]. Available from: https://www.aljazeera.com/indepth/inpictures/rare-lifelesbos-moria-refugee-camp-180119123918846.html

10. European Commission. European Commission - PRESS RELEASES - Press release - Daily News 06 / 02 / 2017 [Internet]. [cited 2019 Jul 11]. Available from: http://europa.eu/rapid/press-release_MEX-17-223_en.htm

11. Leape $\mathrm{S}$, adviser policy. Greece has the means to help refugees on Lesbos but does it have the will? The Guardian [Internet]. 2018. [cited 2019 Jul 24]; Available from: https://www.theguardian.com/global-development/2018/ sep/13/greece-refugees-lesbos-moria-camp-funding-will

12. Refugees overcrowded to 'boiling point' on Greek island, warns UN agency [Internet]. UN News. 2018. [cited 2019 Jul 22]. Available from: https://news. un.org/en/story/2018/08/1018112

13. Jauhiainen JS. Asylum seekers in Lesvos, Greece, 2016-2017. Turku; 2017. ISBN 978-951-29-6857-2.

14. Hermans MPJ, Kooistra J, Cannegieter SC, Rosendaal FR, Mook-Kanamori DO, Nemeth B. Healthcare and disease burden among refugees in long-stay refugee camps at Lesbos, Greece. Eur J Epidemiol. 2017;32(9):851-4. https:// doi.org/10.1007/s10654-017-0269-4.

15. Hémono R, Relyea B, Scott J, Khaddaj S, Douka A, Wringe A. "The needs have clearly evolved as time has gone on.": A qualitative study to explore stakeholders' perspectives on the health needs of Syrian refugees in Greece following the 2016 European Union-Turkey agreement. Confl Heal. 2018; 12(1):24.

16. Kotsiou OS, Kotsios P, Srivastava DS, Kotsios V, Gourgoulianis KI, Exadaktylos AK. Impact of the refugee crisis on the Greek healthcare system: a long road to Ithaca. Int J Environ Res Public Health. 2018;15(8). [cited 2020 Aug 17]. Available from: https://www.ncbi.nlm.nih.gov/pmc/articles/PMC6121252/

17. A Tide of Self-harm and Depression: The EU-Turkey Deal's devastating impact on child refugees and migrants [Internet]. Resource Centre. [cited 2019 Jul 24]. Available from: https://resourcecentre.savethechildren.net/ node/10441/pdf/tide_selfharm_depression.pdf

18. Refugees further traumatized by conditions in Greece's Moria camp | Doctors Without Borders - USA [Internet]. [cited 2020 Aug 19]. Available from: https://www.doctorswithoutborders.org/what-we-do/news-stories/ story/refugees-further-traumatized-conditions-greeces-moria-camp

19. Priebe S, Giacco D, El-Nagib R. Public health aspects of mental health among migrants and refugees: a review of the evidence on mental health care for refugees, asylum seekers and irregular migrants in the WHO European region. Copenhagen: WHO Regional Office for Europe; 2016. [cited 2020 Aug 19]. (WHO Health Evidence Network Synthesis Reports). Available from: http://www.ncbi.nlm.nih.gov/books/NBK391045/

20. Sinnerbrink I, Silove D, Field A, Steel Z, Manicavasagar V. Compounding of premigration trauma and postmigration stress in asylum seekers. J Psychol. 1997;131(5):463-70. https://doi.org/10.1080/00223989709603533.

21. Porter M, Haslam N. Predisplacement and postdisplacement factors associated with mental health of refugees and internally displaced persons: a meta-analysis. JAMA. 2005;294(5):602-12. https://doi.org/10.1 001/jama.294.5.602.

22. Silove $D$, Ventevogel $P$, Rees $S$. The contemporary refugee crisis: an overview of mental health challenges. World Psychiatry. 2017;16(2):130-9. https://doi.org/10.1002/wps.20438.

23. Miller KE, Rasmussen A. The mental health of civilians displaced by armed conflict: an ecological model of refugee distress. Epidemiol Psychiatr Sci. 2017;26(2):129-38. https://doi.org/10.1017/\$2045796016000172.

24. Miller KE, Omidian P, Rasmussen A, Yaqubi A, Daudzai H. Daily stressors, war experiences, and mental health in Afghanistan. Transcult Psychiatry. 2008; 45(4):611-38. https://doi.org/10.1177/1363461508100785.
25. Miller KE, Rasmussen A. War exposure, daily stressors, and mental health in conflict and post-conflict settings: bridging the divide between trauma-focused and psychosocial frameworks. Soc Sci Med 1982. 2010;70(1):7-16.

26. Riley A, Varner A, Ventevogel P, Taimur Hasan MM, Welton-Mitchell C. Daily stressors, trauma exposure, and mental health among stateless Rohingya refugees in Bangladesh. Transcult Psychiatry. 2017;54(3):304-31. https://doi. org/10.1177/1363461517705571.

27. Poole DN, Hedt-Gauthier B, Liao S, Raymond NA, Bärnighausen T. Major depressive disorder prevalence and risk factors among Syrian asylum seekers in Greece. BMC Public Health. 2018;18(1):908.

28. Robjant K, Hassan R, Katona C. Mental health implications of detaining asylum seekers: systematic review. Br J Psychiatry J Ment Sci. 2009;194(4): 306-12. https://doi.org/10.1192/bjp.bp.108.053223.

29. Laban CJ, Gernaat HBPE, Komproe IH, Schreuders BA, De Jong JTVM. Impact of a long asylum procedure on the prevalence of psychiatric disorders in Iraqi asylum seekers in The Netherlands. J Nerv Ment Dis. 2004;192(12):84351. https://doi.org/10.1097/01.nmd.0000146739.26187.15.

30. Keller AS, Rosenfeld B, Trinh-Shevrin C, Meserve C, Sachs E, Leviss JA, et al. Mental health of detained asylum seekers. Lancet Lond Engl. 2003; 362(9397):1721-3. https://doi.org/10.1016/S0140-6736(03)14846-5.

31. Momartin S, Steel Z, Coello M, Aroche J, Silove DM, Brooks R. A comparison of the mental health of refugees with temporary versus permanent protection visas. Med J Aust. 2006;185(7):357-61. https://doi.org/10.5694/ j.1326-5377.2006.tb00610.x

32. Eleftherakos C, van den Boogaard W, Barry D, Severy N, Kotsioni I, RolandGosselin L. 'I prefer dying fast than dying slowly', how institutional abuse worsens the mental health of stranded Syrian, Afghan and Congolese migrants on Lesbos island following the implementation of EU-Turkey deal. Confl Heal. 2018;12:38.

33. Episkopou M, Venables E, Whitehouse K, Eleftherakos C, Zamatto F, de Bartolome GF, et al. In island containment: a qualitative exploration of social support systems among asylum seekers in a mental health care programme on Lesvos Island. Greece Confl Health. 2019;13(1):34. https://doi.org/10.1186/ s13031-019-0218-9.

34. NATIONAL SITUATIONAL PICTURE REGARDING THE ISLANDS AT EASTERN AEGEAN SEA (07/01/2018) [Internet]. [cited 2019 Jul 22]. Available from: http://mindigital.gr/index.php/\%CF\%80\%CF\%81\%CE\%BF\%CF\%83\%CF\%86\% CF\%85\%CE\%B3\%CE\%B9\%CE\%BA\%CF\%8C-\%CE\%B6\%CE\%AE\%CF\%84\%CE\% B7\%CE\%BC\%CE\%B1-refugee-crisis/1854-national-situational-picture-rega rding-the-islands-at-eastern-aegean-sea-07-01-2018

35. Thousands of children in overcrowded Lesbos migrant camp, UNHCR wants to move the most vulnerable [Internet]. InfoMigrants. 2017. [cited $2020 \mathrm{Sep}$ 7]. Available from: https://www.infomigrants.net/en/post/6740/thousands-ofchildren-in-overcrowded-lesbos-migrant-camp-unhcr-wants-to-move-themost-vulnerable

36. Steel Z, Marnane C, Iranpour C, Chey T, Jackson JW, Patel V, et al. The global prevalence of common mental disorders: a systematic review and metaanalysis 1980-2013. Int J Epidemiol. 2014;43(2):476-93. https://doi.org/10.1 093/ije/dyu038.

37. Kessler RC, Angermeyer M, Anthony JC, DE Graaf R, Demyttenaere K, Gasquet I, et al. Lifetime prevalence and age-of-onset distributions of mental disorders in the World Health Organization's world mental health survey initiative. World Psychiatry Off J World Psychiatr Assoc WPA. 2007; 6(3):168-76.

38. Mirowsky J, Ross CE. Age and depression. J Health Soc Behav. 1992;33(3): 187-205; discussion 206-212. https://doi.org/10.2307/2137349.

39. Find Support | NAMI: National Alliance on Mental Illness [Internet]. [cited 2020 Sep 7]. Available from: https://www.nami.org/Support-Education/ Publications-Reports/Guides/Navigating-a-Mental-Health-Crisis

40. Parent MC, Hammer JH, Bradstreet TC, Schwartz EN, Jobe T. Men's mental health help-seeking behaviors: an intersectional analysis. Am J Mens Health. 2018;12(1):64-73. https://doi.org/10.1177/1557988315625776.

41. Saint AD. Cultural determinants of help seeking: a model for research and practice. Res Theory Nurs Pract. 2009;23(4):259-78.

42. Bogic M, Njoku A, Priebe S. Long-term mental health of war-refugees: a systematic literature review. BMC Int Health Hum Rights. 2015;15(1):29. https://doi.org/10.1186/s12914-015-0064-9.

43. Beiser M, Goodwill A, Albanese P, McShane K, Kanthasamy P. Predictors of the integration of Sri Lankan Tamil refugees in Canada: pre-migration adversity, mental health, personal attributes, and post-migration experience. 
Int J Migr Health Soc Care. 2015;11(1):29-44. https://doi.org/10.1108/ IJMHSC-02-2014-0008.

44. Kuehner C. Gender differences in unipolar depression: an update of epidemiological findings and possible explanations. Acta Psychiatr Scand. 2003;108(3):163-74. https://doi.org/10.1034/j.1600-0447.2003.00204.X.

45. Pigott TA. Gender differences in the epidemiology and treatment of anxiety disorders. J Clin Psychiatry. 1999;60(Suppl 18):4-15.

46. Jarallah Y, Baxter J. Gender disparities and psychological distress among humanitarian migrants in Australia: a moderating role of migration pathway? Confl Heal. 2019;13(1):13. https://doi.org/10.1186/ s13031-019-0196-y.

47. Freeman A, Mergl R, Kohls E, Székely A, Gusmao R, Arensman E, et al. A cross-national study on gender differences in suicide intent. BMC Psychiatry. 2017;17(1):234.

48. O'Brien A, Cramer B, Rutherford M, Attard D. A retrospective cohort study describing admissions to a London Trust's PICU beds over one year: do men and women use PICU differently? J Psychiatr Intensive Care. 2013;9(1): 33-9. https://doi.org/10.1017/S1742646412000167.

49. IOM Assessment of Suicide Risks and Factors in a Refugee Camp in Thailand [Internet]. IOM; 2017. [cited 2020 Sep 19]. Available from: https://progressivevoicemyanmar.org/wp-content/uploads/2017/06/IOMMission-in-Thailand-Assessment-of-Suicide-Risks-and-Factors-in-a-RefugeeCamp-in-Thailand.pdf

50. Seedat S, Scott KM, Angermeyer MC, Berglund P, Bromet EJ, Brugha TS, et al. Cross-national associations between gender and mental disorders in the World Health Organization world mental health surveys. Arch Gen Psychiatry. 2009;66(7):785-95. https://doi.org/10.1001/a rchgen psychiatry.2009.36.

51. Dapunt J, Kluge U, Heinz A. Risk of psychosis in refugees: a literature review. Transl Psychiatry. 2017;7(6):e1149.

52. Proudlock S, Peris J. Using EMDR therapy with patients in an acute mental health crisis. BMC Psychiatry. 2020;20(1):14. https://doi.org/10.1186/s12888019-2426-7.

53. Johnson S, Lamb D, Marston L, Osborn D, Mason O, Henderson C, et al. Peer-supported self-management for people discharged from a mental health crisis team: a randomised controlled trial. Lancet Lond Engl. 2018; 392(10145):409-18. https://doi.org/10.1016/S0140-6736(18)31470-3.

54. Three Greek journalists covering migrant crisis arrested for defamation | Reporters without borders [Internet]. RSF. 2018. [cited 2019 Jul 22]. Available from: https://rsforg/en/news/three-greek-journalists-covering-migrantcrisis-arrested-defamation

55. Welle (www.dw.com) D. Arsonists increasingly target refugee shelters in Germany | DW | 12.09.2016 [Internet]. DW.COM. [cited 2020 Sep 19]. Available from: https://www.dw.com/en/arsonists-increasingly-targetrefugee-shelters-in-germany/a-19545693

56. Arson attacks on asylum centres in Sweden. In: Wikipedia [Internet]. 2020. [cited 2020 Sep 19]. Available from: https://en.wikipedia.org/w/index. php?title=Arson_attacks_on_asylum_centres_in_Sweden\&oldid=971925534

\section{Publisher's Note}

Springer Nature remains neutral with regard to jurisdictional claims in published maps and institutional affiliations.

Ready to submit your research? Choose BMC and benefit from:
- fast, convenient online submission
- thorough peer review by experienced researchers in your field
- rapid publication on acceptance
- support for research data, including large and complex data types
- gold Open Access which fosters wider collaboration and increased citations
- maximum visibility for your research: over 100M website views per year
At BMC, research is always in progress.
Learn more biomedcentral.com/submissions

